\title{
ICOM \\ Learning without seeking?: Incidental exposure to science news on social media \& knowledge of gene editing
}

\author{
Joshua T. L. Anderson, Emily L. Howell, Michael A. Xenos, \\ Dietram A. Scheufele and Dominique Brossard
}

\begin{abstract}
Little is known about how incidental exposure to news, interpersonal discussion, and the diversity of social networks interact in social media environments and for science-related issues. Using a U.S. nationally representative survey, we investigate how these features relate to factual knowledge of gene editing. Incidental exposure to science-related news interacts with interpersonal discussion and network heterogeneity and reveals that the relationship between incidental exposure to news and knowledge is strongest among those who discuss the least. Incidental exposure could alleviate knowledge gaps between the Facebook users who are the most and least involved in interpersonal discussions about science.
\end{abstract}

Keywords

DOI

Learning without seeking: incidental exposure to science news on social media may fill knowledge gaps
Public understanding of science and technology; Science communication: theory and models

https://doi.org/10.22323/2.20040201

Submitted: 9th October 2020

Accepted: 4th March 2021

Published: 26th May 2021
Social media and other online media platforms are an increasingly important part of the media landscape, particularly for information on science-related issues [Brossard, 2013; Shearer and Gottfried, 2017]. Yet research is still at the beginning of understanding the implications of these new media environments for public knowledge and discourse in general, let alone for science information. In 2019, 72 percent of all adults, and 90 percent of those aged 19-29, had at least one social media account [Pew Research Center, 2019], up from 50 percent in 2009 [Perrin, 2015]. Of these, Facebook is one of the most popular, with 69 percent of American adults reporting that they use Facebook, and 74 percent of those reporting they do so daily [Pew Research Center, 2019].

Greater social media use also means more Americans report receiving news from social media [Shearer and Matsa, 2018]. According to recent polls, 68 percent of U.S. adults report that they see news on social media sites either purposefully or incidentally [Shearer and Gottfried, 2017]. Online news sources are particularly 
important for information on science and science-related issues, as many traditional outlets such as print newspapers have cut staff at their science desks in the past decade [Brossard, 2013]. Although many Americans do not actively seek out science information, most social media users (79 percent - or 55 percent of U.S. adults) report seeing science-related posts on social media, and 26 percent of users (18 percent of U.S. adults) follow social media pages or accounts that focus on science, according to the most recent polling [Funk, Gottfried and Mitchell, 2017].

The difference between the percent of Americans who reports seeing science information on social media and the percent who actively seeks it out points to an important understudied feature of social media: the potential for incidental exposure to information, particularly science-related information. A growing body of work, particularly in communication and political science, is examining how social media facilitates, or not, incidental exposure - or exposure to information that people were not deliberately seeking out when they went online [Morris and Morris, 2017; Scharkow et al., 2020; Tewksbury, Weaver and Maddex, 2001]. Research suggests that many people often find news on social media without directly seeking it out [Morris and Morris, 2017], and that this incidental exposure has the potential to remedy gaps in knowledge and engagement on political and social issues [Valeriani and Vaccari, 2016] (although this is not always the case e.g., Heiss and Matthes [2019]).

None of the work on incidental exposure, to our knowledge, focuses on its potential relationship to knowledge of science-related issues (though Mueller-Herbst [2019] has examined the relationship of incidental exposure to science news and awareness of gene editing). This is despite evidence that incidental exposure might be an even more important component for how people get science-related news than it is for more general or political news. While polling data indicates that 55 percent of Americans mostly get their online news exposure through incidental exposure, this number increases to 68 percent for science news [Funk, Gottfried and Mitchell, 2017].

In this study, we present a preliminary exploration of the relationship between incidental exposure on one of the largest social media sites - Facebook — and its relationship to knowledge of the emerging science-related issue of gene editing, to address some of these gaps and contribute to the growing body of literature on the impact of incidental exposure on knowledge and engagement on societal issues. Gene editing broadly describes a set of novel technological innovations that allow people to edit the genetic codes of people with higher precision than past technologies [National Academies of Sciences, Engineering, and Medicine, 2017]. Potential applications of gene editing exist in varied fields from medicine to military technology [National Academies of Sciences, Engineering, and Medicine, 2017], but these applications carry with them a wide range of ethical considerations, uncertainties, and opinions shaping public discourse on which applications are acceptable [Scheufele, Xenos et al., 2017]. As the field is quickly advancing, it is an important and timely scientific issue, particularly for understanding how online information exposure can shape knowledge people gain on the topic.

Because likelihood of incidental exposure on social media depends in part on one's social network, we also examine how incidental exposure to science-related information on Facebook relates to two additional important features of social 
media in predicting knowledge of gene editing: 1) the level of heterogeneity within an individual's online social network, and 2) the amount of interpersonal discussion on the topic of gene editing, both on- and offline. Work in political communication has long acknowledged the interaction of news exposure with network heterogeneity [Mutz, 2002; Scheufele, Nisbet et al., 2004] and with interpersonal discussion [Ruggiero, 2000; Hardy and Scheufele, 2005]. We bring these together to provide a first look at how interactions of news exposure, network diversity, and interpersonal discussion matter for the potential impact of science-related information through social media.

\section{Science knowledge through social media}

\section{Why focus on science knowledge}

Knowledge, and its relationship to incidental exposure to online information, is of particular interest to understanding people's views of gene editing. Although just one factor in decision-making, factual knowledge related to an issue does inform deliberation on what courses of action we want to take as a society [Gutmann and Thompson, 2009; Brossard and Lewenstein, 2009]. Gene editing is a complex and value-laden issue that requires public discourse and deliberation on how we want to move forward with the technology across a range of potential and current applications [Burall, 2018]. Many of these decisions will depend on ethical judgements and normative concerns and goals. But factual knowledge about the technology - including how it works and what is technically possible - will also inform decisions on potential paths forward and their possible implications [Renn, 1993]. Additionally, research has found that factual knowledge of gene editing relates to greater support for gene editing development and, importantly to this study, a desire to that such development be informed by public consultation [Scheufele, Xenos et al., 2017].

As an emerging and complex issue, gene editing is also an example of a science issue for which online information sources will be particularly important for people who wish to learn more about the issue. That raises the questions, then, of what the relationship is between social media use and knowledge of gene editing, and how this relates to incidental exposure to science news and participation in discussions concerning the technology.

\section{What is the role of social media in knowledge?}

Although social media is an increasingly important source of information for many Americans, particularly for science news and information on science-related issues, how this information translates into knowledge and attitudes about science issues is less understood. Much of the research on online information environments is through the lens of how online environments either reinforce or alleviate knowledge gaps across groups of people. Some of the factors found to influence knowledge the most are personal factors regarding the individuals who might gain knowledge. For instance, much work points to the motivation or perceived need to learn about a topic as being highly related to knowledge gain [e.g., Garramone, 1984]. Research in science communication specifically also points to individual cultural differences between the information content of science 
messages and the structure of people's world views [Skarlatidou, Cheng and Haklay, 2012].

While much of knowledge gain with respect to science issues is shaped by need, demand, and acceptance of information within a person's cultural worldview, work on knowledge gaps also traces how people with higher education levels or socio-economic status (SES) are often better able to learn from and retain information they come across than are those with lower SES. The result is information exposure can increase, rather than alleviate, knowledge gaps between people with high versus low SES or education [Tichenor, Donohue and Olien, 1970]. Certain news media, such as television, can be more likely to decrease knowledge gaps, perhaps by making the information more accessible to groups with lower SES, while others, such as print newspapers, often heighten gaps [Tichenor, Donohue and Olien, 1970]. For online information, studies indicate that online media have the potential to reduce knowledge gaps, including around science-related issues [Cacciatore, Scheufele and Corley, 2014; Corley and Scheufele, 2010]. How or why this occurs is less examined.

Much of the literature on knowledge and media also focuses on how media choice can also reinforce divides in knowledge, particularly for political issues and often with implications for political participation. For example, Markus Prior's [2007] work illustrates how knowledge of political issues can affect political participation by examining the switch from a mainly low-choice broadcast TV media environment to a high-choice cable environment in the last half of the $20^{\text {th }}$ century. Central to Prior's [2007] research was that increasing media choice worsened knowledge gaps because people chose to not deliberately expose themselves to news as much in high choice environments. Prior's [2007] work focused on the impacts of exposure to information through TV but examined online media use, as well, and found similar results, with online media use decreasing exposure to news. An important feature of understanding modern news environments online, however, is how people may be incidentally exposed to news.

\section{Incidental exposure \& knowledge gaps online}

The internet of the late 1990s and early 2000s that Prior's work examined, however, is very different in its structure and social reach than the internet of today, in large part because of the advent and spread of social media sites. There is increasing evidence that online use and social media in particular allow for incidental exposure to news [Feezell, 2018; Fletcher and Nielsen, 2018; Lu and Lee, 2019; Scharkow et al., 2020; Shearer and Gottfried, 2017], and that this relationship between online media use and likelihood of incidental exposure has greatly increased overtime [Morris and Morris, 2017]. For our purposes, we are less interested in how incidental exposure to social media relates to particular political engagement behaviors and more interested in how it may relate to scientific knowledge, with such knowledge having a role in deliberation of science-related issues in society. Although prior work on incidental exposure has not focused on science news and science-related knowledge, based on the consistent findings throughout literature focused on incidental exposure and increased political knowledge and the relatively greater importance of incidental exposure for coming across science information online [Shearer and Gottfried, 2017], we expect the same 
patterns to hold for incidental exposure and scientific knowledge. In particular, we focus on knowledge of gene editing as a contemporary issue that one could expect to come across in the news and that combines scientific and social concerns. We predict:

H1: Incidental exposure to science-related information on social media will be positively associated with greater gene editing knowledge.

\section{Network heterogeneity}

Of course, incidental exposure online is likely shaped by a number of factors, including one's previous choices in terms of what information they seek out and/or pay attention to. Research in modern media environments in particular often looks at how a person's information ecology is not just shaped by their explicit choice in content, but also implicit choices manifested by curation algorithms, or algorithms that shape what comes on people's social media pages based on what they have posted or paid attention to in the past, what those in their networks are sharing, and others factors that the social media site creators want to prioritize.

Much of the work focusing on the implications of these interactions between users' choices and algorithms in online media focuses on the extent to which these interactions create ideological "filter bubbles" around political issues, or the trend of people to tailor their news networks to low-quality, highly partisan news with those choices then getting reinforced by the sites' algorithms [Pariser, 2011; Flaxman, Goel and Rao, 2016]. There is evidence to suggest that while curation algorithms do not promote homogeneity as a rule, they can be designed in such a way that creates homogeneity in networks [Berman and Katona, 2020; Chitra and Musco, 2020; Li et al., 2019; Min et al., 2019].

This concept of network heterogeneity as important for exposure to a diversity of ideas, and, therefore, as a tool against the dangers of filter bubbles, is a prominent area of study in regards to online news in particular. Much of the research on network heterogeneity focuses on what diversity in on- and offline social networks means for how people engage with political news and discussions. Some studies suggested that people with more diverse networks would lose political interest because of the threat of "cross-cutting" disagreements [Mutz, 2002; Feldman and Price, 2008]. However, other work has suggested that this may not be true if variables such as political knowledge [Scheufele, Nisbet et al., 2004] and frequency of political discussion [Kwak et al., 2005] are accounted for.

The prior research into network heterogeneity is primarily interested in the field of political communication. Because the main drivers identified in the knowledge and participation benefits of network heterogeneity are cross-cutting discussion and diversity of viewpoints [Scheufele, Nisbet et al., 2004] there are challenges in applying the findings from this body of literature on political communication to other domains. In science communication, for instance, people may be less likely to find their friends posting about science issues in the first place. Further, many measures of heterogeneity that focus on political differences may not capture the axes of disagreement for science issues for which opinions are not partisan positions. 
This said, science issues such as gene editing do have disagreement among groups of people that may be represented in other heterogeneity measures, such as diversity in levels of religiosity and education in the U.S. [Scheufele, Xenos et al., 2017]. Therefore, we may expect heterogeneity defined to include these measures of difference to function similarly for science issues as it has been found to function for political issues. Similarly, more diverse networks might mean greater likelihood of being connected to people who pay attention to and share information on different types of topics, such as science issues, even if oneself does not actively seek out information on such issues. These connections could increase the likelihood that one comes across such information in social media. Given as well that evidence from political communication literature suggests that the likelihood and impact of incidental exposure through social media depends at least in part on how diverse one's online social network is [Lee and Kim, 2017; Ahmadi and Wohn, 2018], we therefore predict:

H2: Network heterogeneity will amplify the positive association of incidental exposure to science news and knowledge of gene editing.

\section{On- and offline discussion}

The impact of information encountered online can also depend on the degree to which one then discusses the information with others in their social network, either on- or offline. People who frequently engage in discussion about a topic tend to know more about that topic than those who discuss less often. We see this across science issues such as climate change [Hannibal and Vedlitz, 2018] and infectious disease [Ho, 2012].

There are a number of possible explanations for why discussion positively relates to knowledge. Of course, people who know more might feel more equipped to engage in discussions on a topic. A reverse causal pathway, however - such that people learn from each other through discussion - is supported by empirical studies that suggest interpersonal discussion is associated with issue knowledge even when controlling for factors such as prior knowledge and news use [Eveland and Thomson, 2006]. Another explanation for the relationship between knowledge and discussion of a topic comes from the Uses and Gratifications body of work, which seeks to understand what attracts people to the media they consume [Rubin, 2009]. Uses and Gratifications theory is based on the premise that people do not always consume media solely for information gain but instead can have many separate, often social, reasons and motivations [Rubin, 2009]. These include perceived uses and gratifications related to social interaction, political engagement, group identity, or social capital [Mitchelstein and Boczkowski, 2010; Ruggiero, 2000]. Regardless of the exact pathways at work in the relationship between discussion and knowledge, we expect that:

H3: Participation in interpersonal discussion about science-related issues, both online and offline, will be positively associated with greater factual knowledge about gene editing.

When it comes to how these knowledge and discussion relate to news use, Uses and Gratifications theory has also been applied in political communication research 
to understand news use via the Differential Gains model. The Differential Gains model explains why, even if people read the same news stories, some people gain more knowledge - and by extension become more politically motivated - than others [Scheufele, 2002]. Differential Gains posits that a key mechanism in this process is discussion. People who anticipate that they will be discussing an article will read it more carefully in order to appear more knowledgeable about it and, as a result, gain greater knowledge through the information exposure [Hardy and Scheufele, 2005; Scheufele, 2002]. Therefore, we also predict:

H4: Participation in science discussions will amplify the positive association of incidental exposure to science news and knowledge of gene editing.

Further, because the central premise of the Differential Gains Model is that people generally want to be seen favorably in the eyes of their social network, not all interpersonal discussion may be equal in its effects on information gain. The tendency of discussion anticipation to drive closer reading of news may be especially true if a person anticipates their discussion partner will have a very different opinion from their own [Hardy and Scheufele, 2005]. In other words, if a person expects a challenging argument when they discuss they may be more prone to reading their news carefully than if they expect friendly banter [Hardy and Scheufele, 2005]. Thus, we predict:

H5: Facebook Feed network heterogeneity will interact with participation in science discussions to amplify the positive relationship between incidental exposure to science news and knowledge of gene editing.

To examine these hypotheses, we use survey data from a sample of 1,160 social media users taken from a nationally representative survey of U.S. respondents focused on gene editing attitudes $(n=1600)$ conducted by YouGov from December 2016 to January 2017.

Because these are secondary data gathered for a purpose other than the present study there are limitations to our work that are explained at length in the discussion section. This being said, these data still provide a useful means to start exploring incidental exposure to science news in novel ways.

Only social media users were analyzed for this study because this study is interested in the association of knowledge on social media in particular, based on how users differ across exposure to science-related information, heterogeneous networks, and discussion. Respondents were matched to a sampling frame on gender, age, race, education, political ideology, party affiliation, and political interest to ensure national representativeness based on those characteristics. The completion rate (AAPOR RR6) of this survey was 41.7\%; [Callegaro and DiSogra, 2008].

\section{Analysis}

We used hierarchical ordinary least squares (OLS) regression to test the hypotheses generated for this study. Independent variables were sorted into blocks ordered by 
theoretically derived expected causal order. Block 1 contained demographic variables (age, gender, race, income, and education). Block 2 contained the measure of total attention to science news. Block 3 contained network heterogeneity based on diversity of people who appear on one's Facebook News Feed. Block 4 contained frequency of incidental exposure to science news on social media. Block 5 contained the measure of frequency of discussion of science issues with others. Finally, Blocks 6 and 7 contained interaction variables to examine 1) heterogeneity moderating the effect of incidental exposure on social media to knowledge (H2), 2) frequency of discussion moderating the effect of incidental exposure on social media to knowledge $(\mathrm{H} 3)$, and 3) the three-way interaction between network heterogeneity, incidental exposure, and frequency of discussion on knowledge.

\section{Measures}

The dependent variable is knowledge of gene editing, and it is based on a composite of responses to the following factual statements related to gene editing, using a five-point scale of perceived likelihood that that statement is true $(1=$ "Definitely true", 2 = "Likely true", 3 = "Likely false", 4 = "Definitely false", $9=$ "Don't know"). The battery had nine knowledge items capturing science knowledge and knowledge of advances and news in gene editing at the time of the survey in 2016 across different areas relevant to gene editing:

1. "Over time, human DNA has picked up pieces of DNA from different species and viruses that naturally mixed in with human DNA." (True)

2. "Personal behavior or environmental factors cannot change human DNA." (False)

3. "Ordinary tomatoes do not carry genes, but genetically modified tomatoes do." (F)

4. "Scientists have changed more than 30 genetic characteristics of commercially available plants with gene editing." (T)

5. "Genetically modified crops can be legally grown in all parts of Europe." (F)

6. "Genetically modified foods are currently sold in supermarkets." (T)

7. "To date, no scientists have started human gene editing trials." (F)

8. "Some U.S. universities are currently fighting in court over who owns the patent for the gene editing technology CRISPR-Cas9." (T)

9. "According to scientists, human beings developed from earlier species of animals." (T)

Questions 1, 4, 6, 8, and 9 were dichotomized such that those that answered either "Definitely true" or "Likely true" were considered correct answers.

Questions 2, 3, 5, and 7 were dichotomized such that those that answered either "Definitely false" or "Likely false" were considered correct answers. These 9 items were summed into an index $(M=4.44$, s.d. $=2.58$, Cronbach's alpha $=0.78)$.

A principal component analysis was conducted on these knowledge items. The solution to this principal component analysis was rotated to produce a simpler and 
more interpretable set of results. These results indicated three components with eigenvalues greater than one, with questions $4,6,8$, and 9 loading onto component 1 (22.94\% of total variance explained), questions 3,5 , and 7 loading into component 2 (18.82\% of total variance explained), and questions 1 and 2 loading onto component 3 (13.33\% of total variance explained). Investigation in the component matrix did not reveal any obvious trend of questions belonging to components with respect to topic area. Instead, sorting might be by question difficulty, or possibly by an unknown trend or random chance. Because these questions were meant to capture a wide range of the types of knowledge across different levels of difficulty, it is not surprising that multiple factors can be extracted from these answers. There are limitations from using a summated scale of such knowledge questions to capture "knowledge of gene editing", and the items may in fact be capturing a multidimensional construct with dimensions along unknown lines. For the purposes of this study, however, these existing items can provide a useful starting point for testing how incidental exposure can relate to factual knowledge relevant to understanding the topic of gene editing.

\section{Demographics}

For age, respondents were asked to give their year of birth. This item was then coded into years by subtracting from $2016(M=46.74$, s.d. $=16.75)$. Gender is a dichotomized item coding "female" as 1 , "male" as 0 , and all other responses as missing (52\% female, $48 \%$ male). Race is also dichotomized, coding "white" as 1 , and all other responses as 0 (67\% white, 33\% nonwhite). Education captures respondents' highest level of school completion: "No high school", "High school graduate", "Some college", "2-year", "4-year", and "Post-grad". This item was then coded as a continuous variable from 1 to 6 , respectively $(M=3.28$, s.d. $=1.46)$. Income asked respondents to identify their annual household income from the following list: "Less than \$10,000", “\$10,000-19,999", “\$20,000-29,999", “\$30,000-39,999”, “\$40,000-49,999”, “\$50,000-59,999”, “\$60,000-69,999”, , “\$70,000-79,999”, “\$80,000-99,999”, “\$100,000-119,999”, “\$120,000-149,999”, “\$150,000-199,999”, “\$200,000-249,999”, “\$250,000-349,999”, “\$350,000-499,999”, “\$500,000 or more”. This item was then coded as a continuous variable from 1 to 16 , respectively $(M=5.60$, s.d. $=3.25)$. To fill in missing values, we imputed income using hotdecking [Myers, 2011], with education, race, and gender as donors [Andridge and Little, 2010].

\section{Attention to science news}

To capture total news attention to science-related issues, respondents were asked the following question: "Here are a few questions about your typical use of media. In general, how much attention do you pay to news stories about the following topics? a) Science and technology; b) Political or ethical implications of emerging technologies, such as gene editing; c) New scientific tools or developments, such as CRISPR-Cas9." They were asked to identify their use on a five-point scale ( 1 = "None", 2 = "Very little", 3 = "Some", 4 = "Quite a bit", 5 = "A lot") and their responses were coded 1 through 5 . These items were then averaged into an index of science news attention $(M=2.69$, s.d. $=0.92$, Cronbach's alpha $=0.84)$. 
For incidental exposure to science news on social media in particular, respondents were asked the following question about the frequency at which they encounter science news on social media when using it for a different purpose: "When you use social networks/social media platforms (e.g., Facebook, Twitter, YouTube, etc.), how often do you come across news and information on each of the following when you may have been going online for a purpose other than to get the news?: Recent scientific developments, such as human gene editing." Respondents answered on a five-point scale $(1=$ "Never", 2 = "Sometimes", 3 = "Often", 4 = "Always or very often", and $5=$ "I don't know") and their responses were coded 1 through 4 , with those that responded "I don't know" being excluded $(M=1.80$, s.d. $=0.84)$.

\section{Facebook network heterogeneity \& frequency of discussion}

Respondents (out of those that identified that they used social media) were asked the following to indicate their agreement on a seven-point scale with the following items pertaining the heterogeneity of their Facebook News Feed: "In my Facebook news feed there are people who have different levels of education from me (i.e., high school or less, college or some college, people with advanced degrees)." $(M=5$, s.d. = 1.41), "In my Facebook news feed there are people who are extremely interested in politics, people who couldn't care less, and people in between." $(M=5.59$, s.d. = 1.36), "Many people in my Facebook news feed have political opinions that are very different from mine." $(M=5.01$, s.d. $=1.54)$, "In my Facebook news feed there are a number of political types, including liberals, conservatives, and moderates." $(M=5.14$, s.d. $=1.58)$, "In my Facebook news feed there are a lot of people from different age-groups, ranging from young people, to people who are middle-aged and retirement-age." $(M=5.53$, s.d. $=1.44)$, and "In my Facebook news feed there are people from a diverse mix of racial and ethnic groups." $(M=5.15$, s.d. $=1.53)$. These responses were then averaged into an index $M=5.33$, s.d. $=1.15$, Cronbach's alpha $=0.86)$.

Respondents were asked the following question about the frequency of discussion of science-related issues with other individuals either on- or offline. Respondents were asked to give their answer on a five-point scale (from "Never" to "Very often") and responses were coded from 1 to $5(M=2.49$, s.d. $=1.07)$.

\section{Interactions}

Four interactions were created for this study: 1) incidental exposure to science news ${ }^{*}$ frequency of science discussions, 2) incidental exposure to science news * Facebook feed heterogeneity, 3) frequency of science discussions * Facebook feed heterogeneity, and 4) incidental exposure to science news * frequency of science discussions * Facebook feed heterogeneity. We standardized the component variables prior to making the interactions to reduce multicollinearity between the interactions and the variables capturing the main effects [Aiken, West and Reno, 1991]. To graph the interactions, we used the SPSS PROCESS Macro by Hayes [2017, Model 4], which tests moderation and mediation models and produced values of dependent variable at $-1,0$, and +1 s.d. for the independent and moderating variables [Hayes, Montoya and Rockwood, 2017]. The macro uses bootstraping (5000 samples) and provided the values in Table 1, which we then plotted to create the interactions in Figures 1 and 2. 
Table 1. Variable distributions.

\begin{tabular}{|c|c|c|}
\hline Variable & Mean & $\begin{array}{l}\text { Standard } \\
\text { deviation }\end{array}$ \\
\hline Age & 46.74 & 16.75 \\
\hline Education & 3.28 & 1.46 \\
\hline Income (hotdecked) & 5.60 & 3.25 \\
\hline Attention to science news & 2.69 & .92 \\
\hline Incidental exposure to science news & 1.80 & .84 \\
\hline Facebook network heterogeneity & 5.33 & 1.15 \\
\hline $\begin{array}{l}\text { "In my Facebook news feed there are people who have different levels of } \\
\text { education from me (i.e., high school or less, college or some college, people } \\
\text { with advanced degrees)." }\end{array}$ & 5.00 & 1.41 \\
\hline $\begin{array}{l}\text { "In my Facebook news feed there are people who are extremely interested } \\
\text { in politics, people who couldn't care less, and people in between." }\end{array}$ & 5.59 & 1.36 \\
\hline $\begin{array}{l}\text { "Many people in my Facebook news feed have political opinions that are } \\
\text { very different from mine." }\end{array}$ & 5.01 & 1.54 \\
\hline $\begin{array}{l}\text { "In my Facebook news feed there are a number of political types, including } \\
\text { liberals, conservatives, and moderates." }\end{array}$ & 5.14 & 1.58 \\
\hline $\begin{array}{l}\text { "In my Facebook news feed there are a lot of people from different } \\
\text { age-groups, ranging from young people, to people who are middle-aged } \\
\text { and retirement-age." }\end{array}$ & 5.53 & 1.44 \\
\hline $\begin{array}{l}\text { "In my Facebook news feed there are people from a diverse mix of racial } \\
\text { and ethnic groups." }\end{array}$ & 5.15 & 1.53 \\
\hline Discussion of science issues & 2.49 & 1.07 \\
\hline Knowledge (index) & 4.44 & 2.58 \\
\hline \multicolumn{3}{|l|}{ Dichotomous distributions } \\
\hline Knowledge & Correct & Incorrect \\
\hline $\begin{array}{l}\text { "Over time, human DNA has picked up pieces of DNA from different } \\
\text { species and viruses that naturally mixed in with human DNA." (True) }\end{array}$ & $56.7 \%$ & $43.3 \%$ \\
\hline $\begin{array}{l}\text { "Personal behavior or environmental factors cannot change human DNA." } \\
\text { (False) }\end{array}$ & $61.9 \%$ & $38.1 \%$ \\
\hline $\begin{array}{l}\text { "Ordinary tomatoes do not carry genes, but genetically modified tomatoes } \\
\text { do." (F) }\end{array}$ & $57.6 \%$ & $42.4 \%$ \\
\hline $\begin{array}{l}\text { "Scientists have changed more than } 30 \text { genetic characteristics of } \\
\text { commercially available plants with gene editing." (T) }\end{array}$ & $33.9 \%$ & $66.1 \%$ \\
\hline "Genetically modified crops can be legally grown in all parts of Europe." (F) & $69.4 \%$ & $30.6 \%$ \\
\hline "Genetically modified foods are currently sold in supermarkets." (T) & $23.6 \%$ & $76.4 \%$ \\
\hline "To date, no scientists have started human gene editing trials." (F) & $56.0 \%$ & $44.0 \%$ \\
\hline $\begin{array}{l}\text { "Some U.S. universities are currently fighting in court over who owns the } \\
\text { patent for the gene editing technology CRISPR-Cas9." (T) }\end{array}$ & $54.9 \%$ & $45.1 \%$ \\
\hline $\begin{array}{l}\text { "According to scientists, human beings developed from earlier species of } \\
\text { animals." (T) }\end{array}$ & $41.7 \%$ & $58.3 \%$ \\
\hline \multirow[t]{2}{*}{ Gender } & Female & Male \\
\hline & $52 \%$ & $48 \%$ \\
\hline \multirow[t]{2}{*}{ Race } & White & Nonwhite \\
\hline & $67 \%$ & $33 \%$ \\
\hline
\end{tabular}




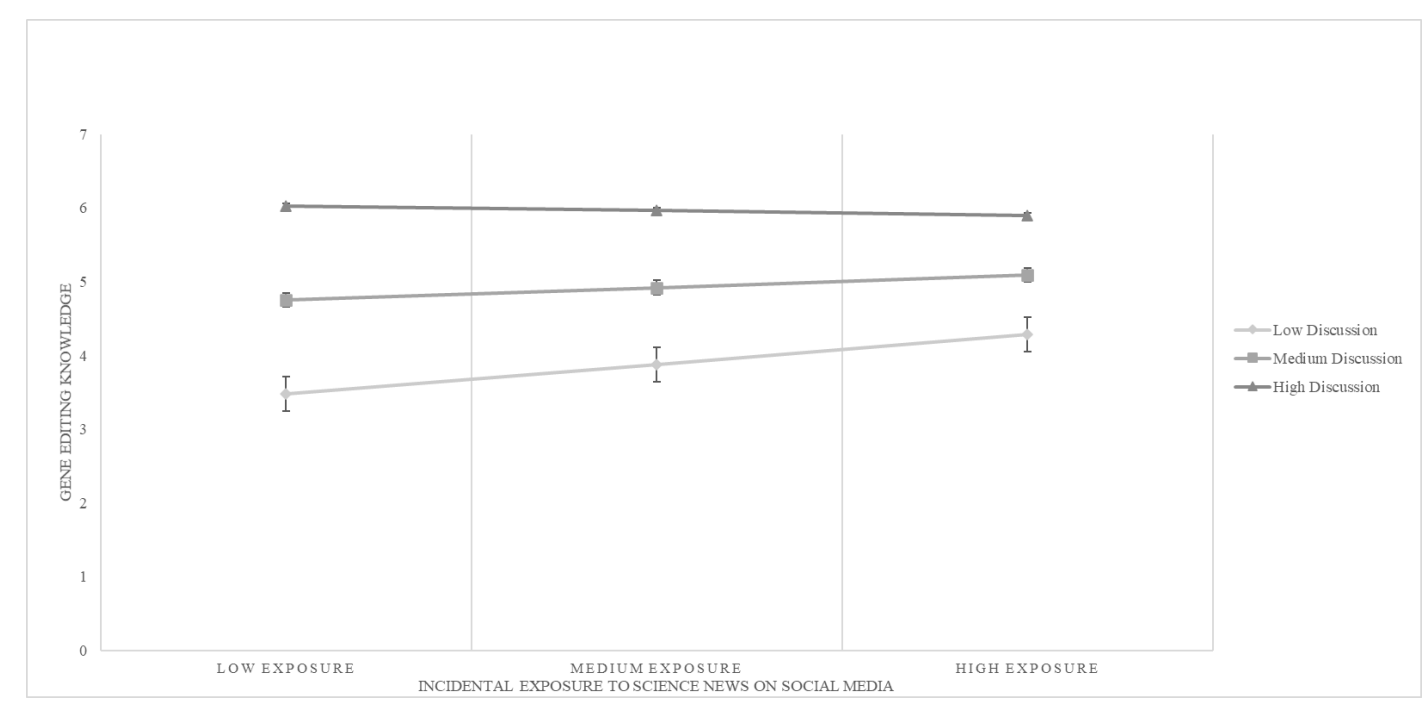

Figure 1. Frequency of science discussions moderating incidental exposure and knowledge.

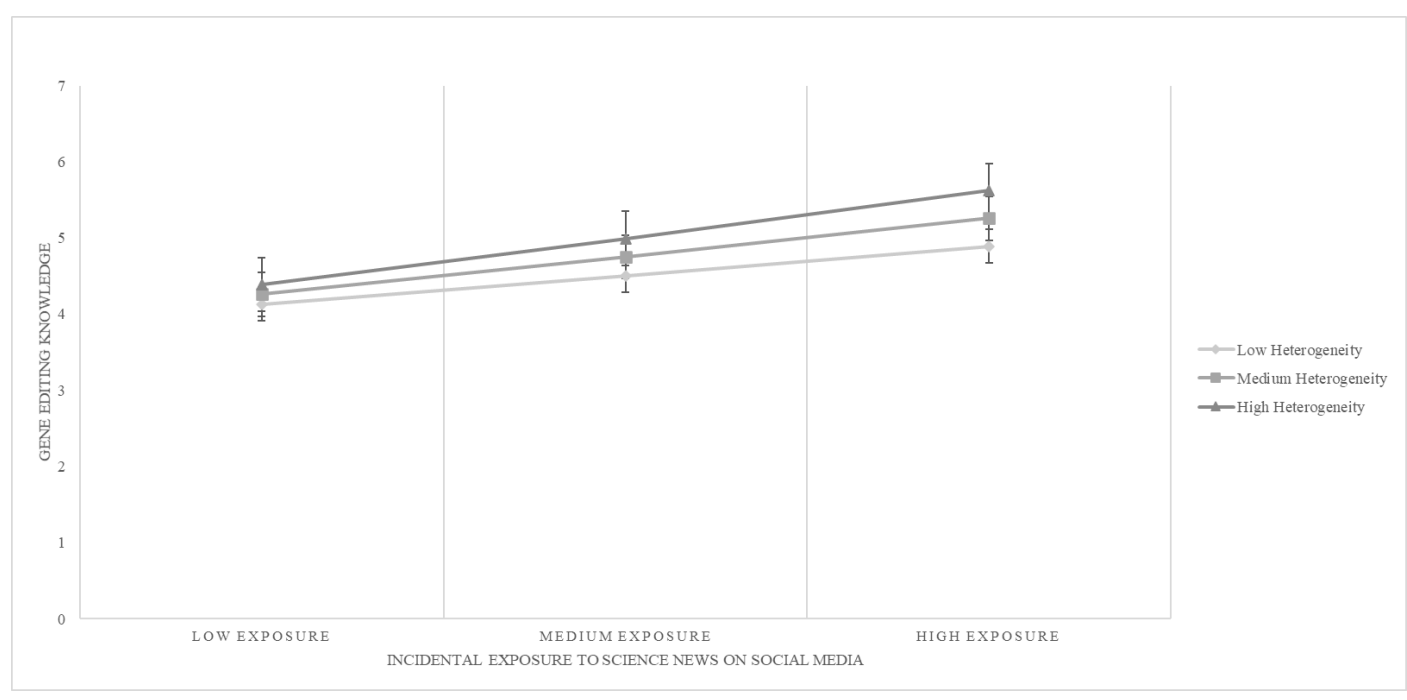

Figure 2. Network heterogeneity moderating incidental exposure and knowledge.

Results

The results of the Hierarchical OLS regression are in Table 2. The model performed well on tests of normality of residuals, homostochasticity, and normality, using as cut-offs 3.3 and -3.3 as suggested by Tabachnick and Fidell [2007]. The model explains approximately 31 percent of the variance in knowledge of gene editing.

The first result to discuss is that incidental science news exposure on social media was significantly related to gene editing knowledge upon entry $(\beta=0.08$, $p<0.01$ ), even after accounting for hard news use. This relationship was not significant in the final model, however. This result suggests that there may be an association between incidental exposure to science news and knowledge of gene editing, but when accounting for other variables in the model there is not evidence for a direct relationship. This result suggests conditional support for hypothesis 1.

Frequency of science discussions was significantly related to knowledge of gene editing in the final model $(\beta=0.26, p<0.001)$. This relationship remained 
Table 2. Results of hierarchical OLS regression.

\begin{tabular}{|c|c|c|c|c|c|c|c|}
\hline & Model 1 & Model 2 & Model 3 & Model 4 & Model 5 & Model 6 & Model 7 \\
\hline \multicolumn{8}{|l|}{$\begin{array}{l}\text { Block 1: } \\
\text { Demographics }\end{array}$} \\
\hline Age & -.032 & $-.067^{* *}$ & $-.066^{*}$ & -.046 & -.030 & -.032 & -.032 \\
\hline Gender & $-.088^{* *}$ & -.040 & $-.059^{*}$ & $-.057^{*}$ & -.045 & -.045 & -.045 \\
\hline Race $(1=$ White $)$ & $.178^{* * *}$ & $.173^{* * *}$ & $.164^{* * *}$ & $.167^{* * *}$ & $.156^{* * *}$ & $.155^{* * *}$ & $.155^{* * *}$ \\
\hline Education & $.257^{* * *}$ & $.185^{* * *}$ & $.182^{* * *}$ & $.180^{* * *}$ & $.139^{* * *}$ & $.131^{* * *}$ & $.131^{* * *}$ \\
\hline Income & $.088^{* *}$ & $.085^{* *}$ & $.078^{* *}$ & $.087^{* *}$ & $.070^{*}$ & $.064^{*}$ & $.063^{*}$ \\
\hline $\begin{array}{l}\text { Block 2: Attention to } \\
\text { science news }\end{array}$ & & $.313^{* * *}$ & $.292^{* * *}$ & $.262^{* * *}$ & $.166^{* * *}$ & $.171^{* * *}$ & $.169^{* * *}$ \\
\hline $\begin{array}{l}\text { Block 3: Facebook } \\
\text { feed heterogeneity }\end{array}$ & & & $.112^{* * *}$ & $.103^{* * *}$ & $.081^{* *}$ & $.084^{* *}$ & $.079^{* *}$ \\
\hline $\begin{array}{l}\text { Block 4: Incidental } \\
\text { exposure to science } \\
\text { news }\end{array}$ & & & & $.083^{* *}$ & .017 & .043 & .043 \\
\hline $\begin{array}{l}\text { Block 5: Frequency } \\
\text { of science discussion }\end{array}$ & & & & & $.258^{* * *}$ & $.255^{* * *}$ & $.254^{* * *}$ \\
\hline \multicolumn{8}{|l|}{$\begin{array}{l}\text { Block 6: First-order } \\
\text { interactions }\end{array}$} \\
\hline $\begin{array}{l}\text { Incidental exposure * } \\
\text { heterogeneity }\end{array}$ & & & & & & $.077^{* *}$ & $.074^{*}$ \\
\hline $\begin{array}{l}\text { Incidental exposure * } \\
\text { discussion }\end{array}$ & & & & & & $-.119^{* * *}$ & $-.122^{* * *}$ \\
\hline $\begin{array}{l}\text { Heterogeneity* } \\
\text { discussion }\end{array}$ & & & & & & -.047 & -.046 \\
\hline \multicolumn{8}{|l|}{$\begin{array}{l}\text { Block 7: } \\
\text { Second-order } \\
\text { interactions }\end{array}$} \\
\hline $\begin{array}{l}\text { Incidental exposure * } \\
\text { heterogeneity * } \\
\text { discussion }\end{array}$ & & & & & & & .013 \\
\hline
\end{tabular}

Notes: $N=1160$. In blocks $1-5$, and 7 , all cell entries are standardized coefficients. In block 6 , cell entries are before-entry coefficients to address multi-collinearity issues between the components of the interaction terms. ${ }^{*} p<.05,{ }^{* *} p<.01,{ }^{* * *} p<.001$.

significant even when accounting for all other variables in the model and suggests evidence of a direct relationship between science discussion frequency and knowledge of gene editing. This result suggests support for hypothesis 3.

In addition to the direct effect of science discussions, frequency of science discussion significantly interacted with incidental news exposure in predicting gene editing knowledge $(\beta=-0.136, p<0.001)$. While we hypothesized a moderating relationship among these variables in hypothesis 4 , the converging direction of relationship is the opposite of what we predicted (Figure 1). Rather than discussion frequency amplifying knowledge among those who were incidentally exposed to information on Facebook, incidental exposure seems to alleviate the gap between those who engage in high and low levels of discussion. In particular, the relationship between incidental exposure to news and knowledge of gene editing was strongest among people who discussed science issues less. This result does not support hypothesis 4 . 
Facebook feed heterogeneity was significantly related to gene editing knowledge in the final model $(\beta=0.09, p<0.001)$. In addition to this direct relationship, network heterogeneity significantly interacted with incidental exposure in predicting gene editing knowledge $(\beta=0.06, p<0.05)$, supporting hypothesis 2 (Figure 2). Incidental exposure to news was more strongly associated with increases in gene editing knowledge for individuals with more heterogeneous Facebook news feeds. The three-way interaction between frequency of science discussions, incidental exposure to science news on social media, and Facebook feed heterogeneity was not significant, however, so the results do not support hypothesis 5 . These results are presented after controlling for race $(\beta=0.16$, $p<0.001)$, education level $(\beta=0.13, p<0.001)$, income $(\beta=0.06, p<0.01)$, and hard science news use $(\beta=0.17, p<.001)$, which collectively explained a large, significant amount of variance in the final model $(23.4 \%)$.

Discussion

Social media sites are a relatively new and popular source of news for Americans, and people often stumble across news stories in their newsfeed that they otherwise would not have sought out. Our study examined how issue knowledge of gene editing might be shaped by incidental exposure to the topic on Facebook - the most popular social media site in the U.S. - focusing as well on how this relationship varies depending on interpersonal discussion and on network heterogeneity.

Before moving to discussion of the results, some limitations to the data and analyses are important to keep in mind. First, as described earlier, this study uses survey data that were collected for a separate original purpose. The data are cross-sectional, and therefore all the relationships captured are correlational - we cannot determine whether they are also causal. Further, some question wording was not tailored to our research questions. For example, our interpersonal discussion item does not differentiate between online and offline discussion. Instead of asking people about their online discussion habits (that could be juxtaposed to online incidental exposure to news), the item captured how much people reported being a discussant in conversations on science-related issues in their day to day lives. This wording, however, had the benefit of allowing us to capture a broader range of potentially relevant behavior and experiences. More useful for future research, then, would be not to focus exclusively on only online behavior, per se, but to include measures that capture and distinguish between onand offline behavior separately to understand their unique effects and any interactions between them.

Our heterogeneity item was also limited but in the opposite direction, where it narrowly captured only Facebook news feed heterogeneity specifically, even while our incidental exposure variable focused on online incidental exposure overall. There may be some concern that this does not capture total online information diversity, which may vary by platform. But focusing on Facebook could also serve as a decent proxy, and as the most popular social media platform, it allows us to understand online heterogeneity for a large part of many Americans' social media experience. The drivers for the hypothesized benefit of heterogeneity for issue knowledge are diversity of opinions and the occurrence of cross-cutting discussions [Scheufele, Nisbet et al., 2004]. Because our heterogeneity measure included areas where there are notable disagreements in regard to human gene editing, in 
particular race and education [Scheufele, Xenos et al., 2017], this measure should work to somewhat simulate diversity of attention to and opinions about gene editing. As we saw in our results, Facebook heterogeneity does seem to relate to and interact with the important variables of focus for the purposes of this study namely knowledge of gene editing and incidental exposure to science news online.

Additionally, our knowledge variable is similarly narrow and is likely missing important aspects of knowledge of gene editing. Focused particularly on factual knowledge of biological processes and contemporary advances in research and applications related to gene editing, we captured only part of the range of relevant science-focused knowledge for insights and discussion into gene editing and its potential implications. Further, knowledge about related topics concerning policymaking, ethical concerns, and the other wide range of ethical, legal, and social aspects of gene editing are relevant to understanding the complex societal issue.

The knowledge composite also likely covers knowledge across a range of dimensions - such as factual specific science knowledge, general science knowledge, and policy-related knowledge, to name just a few. This was an intentional choice in the initial plan for these data to capture knowledge related to gene editing across a number of different topic areas and levels of specificity, but this presents a challenge in this work as the summated knowledge scale appears to show multiple dimensions without a clear, discernable pattern. It would be of interest in future research to develop and test a larger battery of knowledge measures, across different dimensions relevant to gene editing, such as advances in gene editing technology, policy issues, and basics of genetics. This is particularly necessary to better understand what kinds of information might be particularly related to discussion and incidental exposure on science-related topics through Facebook and social media, and see if such work reproduces the relationships we find between incidental exposure and higher knowledge levels. A limitation of our measurement overall in this study also is our reliance on Likert scales. Despite Likert scales being abundant in the field of communication, they may create issues such as forcing equal distances of participant answers for ordinal categories.

A final concern in this study is missing values, based in part on the wording issues described above and the challenges of working with secondary data. While we were interested in social media users specifically, we used an existing nationally representative survey and did not include individuals that did not have social media or Facebook accounts. This cut reduced our original sample size of 1,600 to 1,255 . We did this because although measures like incidental exposure to news would make sense to set to 0 for those who do not use social media (because these individuals are not stumbling across news on social media by definition), other values like network heterogeneity would make very little sense to treat as 0 (because these individuals presumably do not all have completely homogenous networks). This many missing values could be a cause for concern of a biased sample, but the samples before and after the cut was relatively similar. The only significantly different means, as found by t-tests at $\alpha=0.05$, between social media users and non-social media users were attention to science news ( 2.72 and 2.50, respectively), gender (0.53 and 0.42 , respectively), and education (3.32 and 3.02, respectively). 
While our work has a number of limitations as described above, it also offers substantial insights into the potential of social media as a vehicle of science issue knowledge acquisition. The results of this exploratory study presents a strong case for the value of incidental exposure to news as it extends to science-related issues, a previously unexamined area in the larger body of research on incidental exposure on social media, and connects incidental exposure and knowledge to the larger literatures on frequency of discussion and network heterogeneity. We found that heterogeneity of Facebook news feeds and interpersonal discussion of science issues are both significant predictors of gene editing knowledge, even after controlling for both science news attention and incidental exposure to science news. Incidental exposure to science news loaded as a significant predictor of gene editing knowledge (even when controlling for science news attention) but was no longer significant in the model when interpersonal discussion of science issues was included, perhaps because of the converging interaction effect between discussion and incidental exposure. Incidental exposure to science news did significantly interact with both interpersonal discussion of science issues (Figure 1) and Facebook feed heterogeneity (Figure 2).

The interaction between incidental exposure to science news and network heterogeneity shows an amplification relationship. Incidental exposure to science news is most strongly associated with knowledge of gene editing for individuals with more diverse Facebook news feeds. This result was predicted and is more in-line with Scheufele, et al.'s [2004] and Kwak, et al.'s [2005] theoretical framework of network heterogeneity than Mutz's [2002] in finding that heterogeneity seems to relate to outcomes that encourage rather than discourage knowledge gain. It also supports the argument that network diversity is important for news quality, in line with the literature on filter bubbles and the negative effects of network homogeneity on information environments [Pariser, 2011; Flaxman, Goel and Rao, 2016]. This result is unique, however, in that it is evidence of the importance of network diversity for news that is found unintentionally, while previous work has focused on the effects of network heterogeneity on how people intentionally seek out news.

Given the interactions we described earlier between users' past personal choices and what social media site algorithms prioritize showing to users, it is likely that some of the incidental exposure that participants reported was due to their past purposeful exposure to science news and information on social media. That incidental exposure's relationship to knowledge varies depending on the diversity of one's Facebook network, however, also points to the likelihood that people with heterogeneous networks are coming across science-related information they otherwise would not see.

The significant interaction between incidental exposure and network discussion was in a more surprising direction. We hypothesized that, like network heterogeneity, interpersonal discussion of science news would have an amplification relationship with incidental exposure to science news on gene editing knowledge. This hypothesized relationship would be in-line with previous work on Differential Gains models that suggest people read news more carefully if they anticipate interpersonal discussion about the topics covered in the news articles [Scheufele, 2002; Hardy and Scheufele, 2005]. This relationship is thought to be especially true if someone expects disagreement because they have a more 
heterogenous social network [Hardy and Scheufele, 2005]. Thus, we hypothesized a three-way interaction among incidental exposure to news, interpersonal discussion of science issues, and network heterogeneity on gene editing knowledge. This interaction did not end up being significant in our model.

Although the two-way interaction between interpersonal discussion of science issues and incidental exposure to news was significant, it did not reveal an amplification effect (Figure 1). Instead, the relationship between incidental exposure to news and gene editing knowledge was strongest among people who discussed the least about science issues - resulting in convergence among people who reported high and low levels of interpersonal discussion about science issues. There is a substantial body of work that suggests a consistent positive relationship between discussion and knowledge [Holbert et al., 2002; Eveland and Thomson, 2006; Hannibal and Vedlitz, 2018; Ho, 2012], as captured also by Uses and Gratifications and the Differential Gains models [Scheufele, 2002; Hardy and Scheufele, 2005]. What this result may suggest is that instead of heightening knowledge gaps, incidental exposure to news may fill in an existing knowledge gap between frequent and rare discussants of science.

This result is again an argument for the importance of incidental exposure to news. Knowledge gaps exist along a number of axes, and people who are traditionally uninformed (in this case people who do not often discuss issues) may learn about issues by accident. The results also highlight how models focused on deliberate information gain - such as Differential Gains models - might be less appropriate for anticipating the effects of incidental information gain.

Of course, here as well we need more research in these areas to start to better understand the many intertwined factors shaping what people see on social media, particularly work that allows us to trace causal pathways, including to see to what extent incidental exposure is determined by past purposeful information seeking. Importantly, however, the significant interaction between incidental exposure and interpersonal discussion suggests that although being incidentally exposed to news does not necessarily translate to more knowledge for those already engaged with an issue, it may fill in a knowledge gap between individuals who frequently discuss issues and those that seldom do. The results could provide insight, as well, into how internet use could be alleviating knowledge gaps, as others have found to be the case, particularly for science issues [Corley and Scheufele, 2010; Cacciatore, Scheufele and Corley, 2014]. Perhaps not everyone learns from news that they just so happen to run into on the internet, but, with diverse networks in particular, incidental exposure could be a significant source of science information and knowledge for traditionally less science-seeking people.

Conclusion

Incidental exposure can be a vital part of people's information environments, particularly for knowledge outcomes, and social media appears to be conducive to creating opportunities for such exposure. Evidence suggests this is especially the case for information on science-related issues, much of which is increasingly available only online and which people might be less likely to actively seek out than they are for other news topics and entertainment. The incidental exposure, in turn, seems to be a possible mechanism for reducing knowledge gaps between the 
more- and less-engaged in discussions on a topic. Its relationship to knowledge also appears to relate to how diverse one's network on a social media site is.

Research is increasingly finding how social media, and online media in general, are neither a poison nor a panacea for access to accurate knowledge. Despite being ignored by much of the body of work contending with science issues, incidental exposure seems to be a particularly important aspect of these environments. Given the dearth of research on science-related information in particular and the importance of online, and incidental, exposure for science information, we especially need work expanding from this study to understand how incidental exposure online matters for knowledge and engagement in science-related issues. With how intertwined many urgent and complex societal issues are with science and technology — such as gene editing, artificial intelligence, and the COVID-19 pandemic - work on what information we all stumble across online and what this means for our understandings and engagement on these issues is especially timely and necessary. With this first exploration, we present what we hope to be a seed for such work. Incidental exposure to science news is a relatively unexplored course of study, but our results suggest that it may yet be a fruitful one.

\section{References}

Ahmadi, M. and Wohn, D. Y. (2018). 'The antecedents of incidental news exposure on social media'. Social Media + Society 4 (2). https://doi.org/10.1177/2056305118772827.

Aiken, L. S., West, S. G. and Reno, R. R. (1991). Multiple regression: testing and interpreting interactions. Thousand Oaks, CA, U.S.A.: SAGE Publications.

Andridge, R. R. and Little, R. J. A. (2010). 'A review of hot deck imputation for survey non-response'. International Statistical Review 78 (1), pp. 40-64. https://doi.org/10.1111/j.1751-5823.2010.00103.x.

Berman, R. and Katona, Z. (2020). 'Curation algorithms and filter bubbles in social networks'. Marketing Science 39 (2), pp. 296-316. https://doi.org/10.1287/mksc . 2019.1208.

Brossard, D. (2013). 'New media landscapes and the science information consumer'. Proceedings of the National Academy of Sciences 110 (Supplement 3), pp. 14096-14101. https://doi.org/10.1073/pnas.1212744110.

Brossard, D. and Lewenstein, B. V. (2009). 'A critical appraisal of models of public understanding of science: using practice to inform theory'. In: Communicating science. New agendas in communication. Ed. by L. Kahlor and P. A. Stout. New York, U.S.A.: Routledge, pp. 11-39.

Burall, S. (2018). 'Rethink public engagement for gene editing'. Nature 555 (7697), pp. 438-439. https://doi.org/10.1038/d41586-018-03269-3.

Cacciatore, M. A., Scheufele, D. A. and Corley, E. A. (2014). 'Another (methodological) look at knowledge gaps and the Internet's potential for closing them'. Public Understanding of Science 23 (4), pp. 376-394. https://doi.org/10.1177/0963662512447606.

Callegaro, M. and DiSogra, C. (2008). 'Computing response metrics for online panels'. Public Opinion Quarterly 72 (5), pp. 1008-1032. https://doi.org/10.1093/poq/nfn065.

Chitra, U. and Musco, C. (2020). 'Analyzing the impact of filter bubbles on social network polarization'. In: WSDM '20: Proceedings of the 13th International Conference on Web Search and Data Mining, pp. 115-123. https://doi.org/10.1145/3336191.3371825. 
Corley, E. A. and Scheufele, D. A. (2010). 'Outreach going wrong? When we talk nano to the public, we are leaving behind key audiences'. The Scientist 24 (1), 22.

Eveland, W. P. and Thomson, T. (2006). 'Is it talking, thinking, or both? A lagged dependent variable model of discussion effects on political knowledge'. Journal of Communication 56 (3), pp. 523-542.

https://doi.org/10.1111/j.1460-2466.2006.00299.x.

Feezell, J. T. (2018). 'Agenda setting through social media: The importance of incidental news exposure and social filtering in the digital era'. Political Research Quarterly 71 (2), pp. 482-494. https: //doi.org/10.1177/1065912917744895.

Feldman, L. and Price, V. (2008). 'Confusion or enlightenment?: how exposure to disagreement moderates the effects of political discussion and media use on candidate knowledge'. Communication Research 35 (1), pp. 61-87. https://doi.org/10.1177/0093650207309362.

Flaxman, S., Goel, S. and Rao, J. M. (2016). 'Filter bubbles, echo chambers, and online news consumption'. Public Opinion Quarterly 80 (S1), pp. 298-320. https://doi.org/10.1093/poq/nfw006.

Fletcher, R. and Nielsen, R. K. (2018). 'Are people incidentally exposed to news on social media? A comparative analysis'. New Media E Society 20 (7), pp. 2450-2468. https://doi.org/10.1177/1461444817724170.

Funk, C., Gottfried, J. and Mitchell, A. (20th September 2017). 'Science news and information today'. Pew Research Center Journalism $\mathcal{E}$ Media. URL: http: //www . j ournalism.org/2017/09/20/science-news-and-information-today/.

Garramone, G. M. (1984). 'Audience motivation effects: more evidence'. Communication Research 11 (1), pp. 79-96. https://doi.org/10.1177/009365084011001004.

Gutmann, A. and Thompson, D. F. (2009). Why deliberative democracy? Princeton, NJ, U.S.A.: Princeton University Press.

Hannibal, B. and Vedlitz, A. (2018). 'Social capital, knowledge, and the environment: the effect of interpersonal communication on climate change knowledge and policy preferences'. Sociological Spectrum 38 (4), pp. 277-293. https://doi.org/10.1080/02732173.2018.1502108.

Hardy, B. W. and Scheufele, D. A. (2005). 'Examining differential gains from Internet use: comparing the moderating role of talk and online interactions'. Journal of Communication 55 (1), pp. 71-84.

https://doi.org/10.1111/j.1460-2466.2005.tb02659.x.

Hayes, A. F. (2017). Introduction to mediation, moderation, and conditional process analysis: a regression-based approach. New York, NY, U.S.A.: Guilford Press.

Hayes, A. F., Montoya, A. K. and Rockwood, N. J. (2017). 'The analysis of mechanisms and their contingencies: PROCESS versus structural equation modeling'. Australasian Marketing Journal 25 (1), pp. 76-81. https://doi.org/10.1016/j.ausmj.2017.02.001.

Heiss, R. and Matthes, J. (2019). 'Does incidental exposure on social media equalize or reinforce participatory gaps? Evidence from a panel study'. New Media $\mathcal{E}$ Society 21 (11-12), pp. 2463-2482. https://doi.org/10.1177/1461444819850755.

Ho, S. S. (2012). 'The knowledge gap hypothesis in Singapore: the roles of socioeconomic status, mass media, and interpersonal discussion on public knowledge of the H1N1 flu pandemic'. Mass Communication and Society 15 (5), pp. 695-717. https://doi.org/10.1080/15205436.2011.616275. 
Holbert, R. L., Benoit, W., Hansen, G. and Wen, W.-C. (2002). 'The role of communication in the formation of an issue-based citizenry'. Communication Monographs 69 (4), pp. 296-310. https://doi.org/10.1080/03637750216549.

Kwak, N., Williams, A. E., Wang, X. and Lee, H. (2005). 'Talking politics and engaging politics: an examination of the interactive relationships between structural features of political talk and discussion engagement'. Communication Research 32 (1), pp. 87-111. https: //doi .org/10.1177/0093650204271400.

Lee, J. K. and Kim, E. (2017). 'Incidental exposure to news: predictors in the social media setting and effects on information gain online'. Computers in Human Behavior 75, pp. 1008-1015. https://doi.org/10.1016/j.chb.2017.02.018.

Li, K. G., Mithas, S., Zhang, Z. and Tam, K. Y. (2019). 'Does algorithmic filtering create a filter bubble? Evidence from Sina Weibo'. Academy of Management Proceedings 2019 (1), 14168. https://doi.org/10.5465/AMBPP. 2019.14168abstract.

Lu, Y. and Lee, J. K. (2019). 'Stumbling upon the other side: incidental learning of counter-attitudinal political information on Facebook'. New Media E Society 21 (1), pp. 248-265. https://doi.org/10.1177/1461444818793421.

Min, Y., Jiang, T., Jin, C., Li, Q. and Jin, X. (2019). 'Endogenetic structure of filter bubble in social networks'. Royal Society Open Science 6 (11), 190868. https://doi.org/10.1098/rsos.190868.

Mitchelstein, E. and Boczkowski, P. J. (2010). 'Online news consumption research: an assessment of past work and an agenda for the future'. New Media $\mathcal{E}$ Society 12 (7), pp. 1085-1102. https://doi .org/10.1177/1461444809350193.

Morris, D. S. and Morris, J. S. (2017). 'Evolving learning: the changing effect of internet access on political knowledge and engagement (1998-2012)'. Sociological Forum 32 (2), pp. 339-358. https://doi.org/10.1111/socf. 12333.

Mueller-Herbst, J. (2019). 'Saw it on Facebook: does social media use predict awareness of human gene editing?' In: NCA 105th Annual Convention: Communication for Survival (Baltimore, MD, U.S.A. 14th-17th November 2019).

Mutz, D. C. (2002). 'The consequences of cross-cutting networks for political participation'. American Journal of Political Science 46 (4), pp. 838-855. https://doi.org/10.2307/3088437.

Myers, T. A. (2011). 'Goodbye, listwise deletion: presenting hot deck imputation as an easy and effective tool for handling missing data'. Communication Methods and Measures 5 (4), pp. 297-310. https://doi.org/10.1080/19312458.2011.624490.

National Academies of Sciences, Engineering, and Medicine (2017). Human genome editing: science, ethics, and governance. Washington, DC, U.S.A.: The National Academies Press. https://doi .org/10.17226/24623.

Pariser, E. (2011). The filter bubble: how the new personalized web is changing what we read and how we think. London, U.K.: Penguin.

Perrin, A. (8th October 2015). 'Social media usage: 2005-2015'. Pew Research Center Internet $\mathcal{E}$ Technology. URL: https: //www . pewresearch.org/internet/2015/10 /08/social-networking-usage-2005-2015/.

Pew Research Center (2019). 'Demographics of social media users and adoption in the United States'. Pew Research Center Internet \& Technology. URL: https://www. pewresearch.org/internet/fact-sheet/social-media/ (visited on 13th November 2019). 
Prior, M. (2007). Post-broadcast democracy: how media choice increases inequality in political involvement and polarizes elections. New York, NY, U.S.A.: Cambridge University Press. https://doi .org/10.1017/CB09781139878425.

Renn, O. (1993). 'The social arena concept of risk debates'. In: Social theories of risk. Ed. by S. Krimsky. Westport, CT, U.S.A.: Praeger Publishers, pp. 179-196. https://doi.org/10.18419/opus-7275.

Rubin, A. M. (2009). 'Uses-and-gratifications perspective on media effects'. In: Media effects: advances in theory and research. Ed. by J. Bryant and M. B. Oliver. New York, NY, U.S.A.: Routledge, pp. 181-200. https://doi.org/10.4324/9780203877111.

Ruggiero, T. E. (2000). 'Uses and gratifications theory in the 21st century'. Mass Communication and Society 3 (1), pp. 3-37. https://doi.org/10.1207/S15327825MCS0301_02.

Scharkow, M., Mangold, F., Stier, S. and Breuer, J. (2020). 'How social network sites and other online intermediaries increase exposure to news'. Proceedings of the National Academy of Sciences 117 (6), pp. 2761-2763. https://doi.org/10.1073/pnas.1918279117.

Scheufele, D. A. (2002). 'Examining differential gains from mass media and their implications for participatory behavior'. Communication Research 29 (1), pp. 46-65. https://doi.org/10.1177/009365020202900103.

Scheufele, D. A., Nisbet, M. C., Brossard, D. and Nisbet, E. C. (2004). 'Social structure and citizenship: examining the impacts of social setting, network heterogeneity, and informational variables on political participation'. Political Communication 21 (3), pp. 315-338. https://doi.org/10.1080/10584600490481389.

Scheufele, D. A., Xenos, M. A., Howell, E. L., Rose, K. M., Brossard, D. and Hardy, B. W. (2017). 'U.S. attitudes on human genome editing'. Science 357 (6351), pp. 553-554. https://doi.org/10.1126/science.aan3708.

Shearer, E. and Gottfried, J. (7th September 2017). 'News use across social media platforms 2017'. Pew Research Center Journalism \& Media. URL: http: //www . jour nalism.org/2017/09/07/news-use-across-social-media-platforms-2017/.

Shearer, E. and Matsa, K. E. (10th September 2018). 'News use across social media platforms 2018'. Pew Research Center Journalism \& Media. URL: https://www . jou rnalism . org/2018/09/10/news-use-across-social-media-platforms-2018/.

Skarlatidou, A., Cheng, T. and Haklay, M. (2012). 'What do lay people want to know about the disposal of nuclear waste? A mental model approach to the design and development of an online risk communication'. Risk Analysis 32 (9), pp. 1496-1511. https://doi.org/10.1111/j.1539-6924.2011.01773.x.

Tabachnick, B. G. and Fidell, L. S. (2007). Using multivariate statistics. Boston, MA, U.S.A.: Pearson, pp. 481-498.

Tewksbury, D., Weaver, A. J. and Maddex, B. D. (2001). 'Accidentally informed: incidental news exposure on the world wide web'. Journalism $\mathcal{E}$ Mass Communication Quarterly 78 (3), pp. 533-554. https://doi.org/10.1177/107769900107800309.

Tichenor, P. J., Donohue, G. A. and Olien, C. N. (1970). 'Mass media flow and differential growth in knowledge'. Public Opinion Quarterly 34 (2), pp. 159-170. https://doi.org/10.1086/267786.

Valeriani, A. and Vaccari, C. (2016). 'Accidental exposure to politics on social media as online participation equalizer in Germany, Italy, and the United Kingdom'. New Media E Society 18 (9), pp. 1857-1874. https://doi.org/10.1177/1461444815616223. 
Joshua Anderson is a Ph.D. student in the School of Advertising at the University of Texas at Austin and a former MS student and researcher with the Life Sciences Communication department at the University of Wisconsin-Madison. His research interests focus on science engagement in new media spaces.

E-mail: jtlanderson@utexas.edu.

Emily L. Howell is the Civic Science Postdoctoral Fellow at the University of Wisconsin-Madison. Her work focuses on communication and decision-making in controversial science and policy issues. E-mail: elhowell@wisc.edu.

Michael A. Xenos is a Professor in the Department of Life Sciences Communication, as well as Professor of Communication Science in the Department of Communication Arts at the University of Wisconsin-Madison. His research and teaching focuses on the effects of new media on political engagement, opinion formation, and public deliberation, particularly surrounding emerging science and technology issues. E-mail: xenos@wisc.edu.

Dietram A. Scheufele is the Taylor-Bascom Chair in Science Communication and Vilas Distinguished Achievement Professor at the University of Wisconsin-Madison and in the Morgridge Institute for Research. His work examines the social effects of emerging science and technology. E-mail: scheufele@wisc.edu.

Dominique Brossard is chair and a professor in the Department of Life Sciences Communication and in the Morgridge Institute for Research at the University of Wisconsin-Madison. Her research program focuses on the intersection between science, media, and policy in the context of controversial scientific innovations. E-mail: dbrossard@wisc.edu.

\section{How to cite}

Anderson, J. T. L., Howell, E. L., Xenos, M. A., Scheufele, D. A. and Brossard, D. (2021). 'Learning without seeking?: Incidental exposure to science news on social media \& knowledge of gene editing'. JCOM 20 (04), A01. https://doi.org/10.22323/2.20040201. 